\title{
Identification and Functional Analysis of Mutations in the Hypocretin (Orexin) Genes of Narcoleptic Canines
}

\author{
Marcel Hungs, ${ }^{1,3}$ Jun Fan, ${ }^{2,3}$ Ling Lin, ${ }^{1}$ Xiaoyan Lin, ${ }^{1}$ Richard A. Maki, ${ }^{2}$ and \\ Emmanuel Mignot ${ }^{1,4}$ \\ ${ }^{1}$ Stanford Center for Narcolepsy, Stanford University Medical Center, Department of Psychiatry and Behavioral Sciences, Palo \\ Alto, California 94304-5485, USA; ${ }^{2}$ Neurocrine Biosciences, San Diego, California 92121, USA
}

\begin{abstract}
Narcolepsy is a sleep disorder affecting animals and humans. Exon skipping mutations of the Hypocretin/Orexin-receptor-2 (Hcrtr2) gene were identified as the cause of narcolepsy in Dobermans and Labradors. Preprohypocretin (Hcrt) knockout mice have symptoms similar to human and canine narcolepsy. In this study, 11 sporadic cases of canine narcolepsy and two additional multiplex families were investigated for possible Hcrt and Hcrtr2 mutations. Sporadic cases have been shown to have more variable disease onset, increased disease severity, and undetectable Hypocretin-1 levels in cerebrospinal fluid. The canine Hcrt locus was isolated and characterized for this project. Only one novel mutation was identified in these two loci. This alteration results in a single amino acid substitution (E54K) in the N-terminal region of the Hcrtr2 receptor and autosomal recessive transmission in a Dachshund family. Functional analysis of previously-described exon-skipping mutations and of the E54K substitution were also performed using HEK-293 cell lines transfected with wild-type and mutated constructs. Results indicate a truncated Hcrtr2 protein, an absence of proper membrane localization, and undetectable binding and signal transduction for exon-skipping mutated constructs. In contrast, the E54K abnormality was associated with proper membrane localization, loss of ligand binding, and dramatically diminished calcium mobilization on activation of the receptor. These results are consistent with a loss of function for all three mutations. The absence of mutation in sporadic cases also indicates genetic heterogeneity in canine narcolepsy, as reported previously in humans.
\end{abstract}

Narcolepsy is a neurological sleep disorder affecting humans and animals (Baker et al. 1982; Mignot et al. 1992; Aldrich 1998). It is characterized by excessive daytime sleepiness and symptoms of abnormal rapideye-movement (REM) sleep (cataplexy, hypnagogic hallucinations, and sleep paralysis). Cataplexy is a sudden loss of muscle tone triggered by emotions that share some physiological similarities with REM sleep atonia. This symptom is the most valuable clinical feature used to diagnose narcolepsy in humans and animals (Nishino and Mignot 1997; Anic-Labat et al. 1999).

Canine and human narcolepsy are strikingly similar at the clinical and genetic epidemiological level. Most cases of human and canine narcolepsy are sporadic in nature (Baker et al. 1982; Mignot et al. 1992; Mignot 1998). Familial clustering suggestive of highly penetrant narcolepsy genes is observed occasionally in both human and canines. Human narcolepsy is tightly associated with HLA-DQB1*0602 and has been sug-

\footnotetext{
${ }^{3}$ These authors contributed equally to this work.

${ }^{4}$ Corresponding author.

E-MAIL mignot@stanford.edu; FAX (650) 498-7761.

Article published on-line before print: Genome Res., 10.1101/gr.161001.

Article and publication are at www.genome.org/cgi/doi/10.1101/ gr.161001.
}

gested to be autoimmune in nature (Mignot et al. 1995, 2001). In contrast, canine narcolepsy is not associated with specific dog leukocyte antigen (DLA) -DQ alleles (Wagner et al. 2000), but the involvement of other major histocompatibility complex (MHC) loci remains to be investigated.

Recent studies have implicated Hypocretin (also called Orexin) abnormalities in both human and canine narcolepsy (Lin et al. 1999; Nishino et al. 2000; Peyron et al. 2000; Thannickal et al. 2000; Ripley et al. 2001). In Dobermans and Labradors, familial canine narcolepsy is caused by exon-skipping mutations of the Hcrtr2 (Lin et al. 1999). Sporadic human narcolepsy-cataplexy is associated with dramatically decreased Hcrt transcript and peptides in brain and CSF (Nishino et al. 2000; Peyron et al. 2000; Thannickal et al. 2000). This result parallels recent findings indicating undetectable CSF Hcrt-1 levels in two sporadic canine narcolepsy cases but not in Hcrtr2-mutated canines (Nishino et al. 2000; Ripley et al. 2001).

The majority of familial and sporadic cases of human narcolepsy lack Hcrt system gene mutations. In a recent study including 74 patients of various HLA and family history status, only one mutation was observed in the signal peptide of the Hcrt locus in a child with 
early onset and severe narcolepsy-cataplexy (Peyron et al. 2000). Mutations in the two Hypocretin receptor genes, Hcrtr1 and Hcrtr2, were not observed. In this study, we characterized the dog Hcrt locus and sequenced the Hcrt and Hcrtr2 loci in sporadic and familial cases of dog narcolepsy to identify potential mutations.

\section{RESULTS}

\section{Isolation and Characterization of the Canine Hcrt and Hcrtr2 Loci}

A total of 16 bacterial artificial chromosome (BAC) clones covering the Hcrtr2 locus and its immediate vicinity were isolated (Fig. 1A). Seven canine Hcrtpositive BAC clones covering $\sim 200 \mathrm{~kb}$ (Fig. 1B) were isolated by library screening as described in the Methods section. The canine Hcrtr2 locus has been previously described (Lin et al. 1999), but approximate exon locations are now reported (Fig. 1A). A sequence of 1961 bp encompassing the newly isolated canine Hcrt gene including exon 1 , exon 2 , intron, and flanking sequences has been submitted to GenBank (accession no. AF285110). The locus is organized similarly to the human locus (Sakurai et al. 1998). Exon 2 encompasses the full sequence of both the Hcrt-1 and Hcrt-2 peptides. The predicted mature amino acid sequence of canine Hcrt- 1 is identical to human, rat, pig , and mouse sequences, while canine Hcrt- 2 differs from the human sequence by one amino acid (S71P; Fig. 2). We also isolated and mapped three novel microsatellite polymorphic markers in the vicinity of Hcrt.

\section{Mutation Screening of Hcrt and Hcrtr2 in Canine Narcolepsy}

The seven exons of Hcrtr2 and two exons of Hcrt were screened by sequencing PCR products encompassing the exons and a minimum of $50 \mathrm{bp}$ of flanking sequence on both sides. Seven Hcrtr 2 and three Hcrt polymorphisms were observed in 17 narcoleptic dogs, 28 unrelated controls, and 15 related asymptomatic dogs. All polymorphisms but one were benign, being observed in both asymptomatic and narcoleptic animals. Most of these polymorphisms were common in controls and unrelated narcoleptic animals across several breeds. Allele frequencies in unrelated control Poodles (10 animals, P), Dachshunds (9, Da), Dobermans (7, Do), and Labradors (2, L) were Hcrtr2 Exon $126 \mathrm{G} \rightarrow \mathrm{C}$ (P: 0.50, Da: 0.33, Do: 0.78, L: 0.75); Hcrtr2 Exon 1 202TCG $\rightarrow$ deletion (P: 0.50, Da: 0.17, Do: 0.71, L: 0.00); Hcrtr2 Exon $215 \mathrm{~T} \rightarrow \mathrm{C}$ (P: 0.50, Da: 0.89, Do: 0.36, L: 0.00); Hcrtr2 Exon $2111 \mathrm{~A} \rightarrow \mathrm{G}$ (P: 0.50, Da: 0.12, Do: 0.57, L: 1.00); Hcrtr2 Exon $5+61 \mathrm{C} \rightarrow \mathrm{T}(\mathrm{P}:$ 1.00, Da: 0.89, Do: 1.00, L: 0.50); Hcrtr2 Exon 6 $-64 \mathrm{~A} \rightarrow \mathrm{G}$ (P: 0.55, Da: 0.39, Do: 0.71, L: 0.75); Hcrt Exon $257 \mathrm{G} \rightarrow \mathrm{T}$ (P: 0.00, Da: 0.00, Do: 0.00, L: 0.25).
A
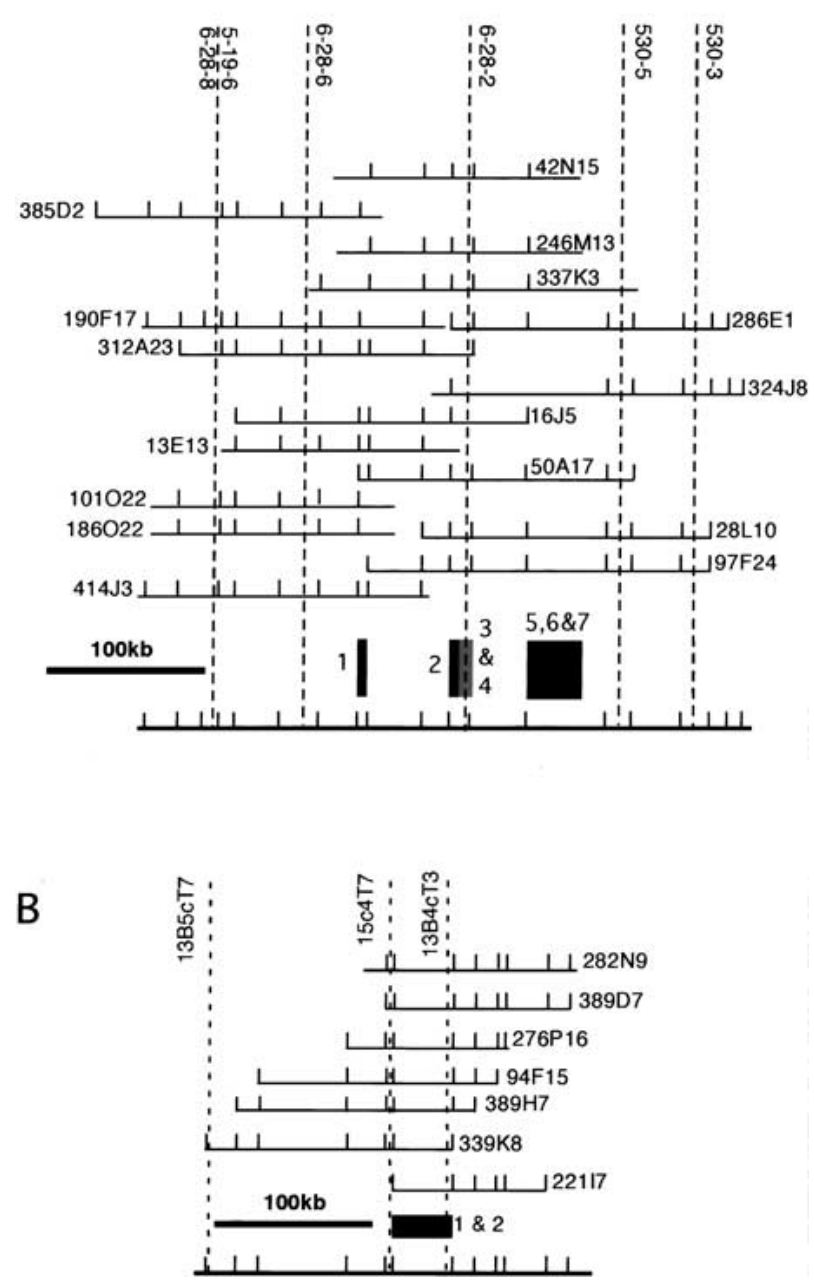

Figure 1 Canine BAC clone contigs encompassing the Hcrtr2 locus $(A)$ and $H c r t(B)$. Approximate exon locations are indicated by dark boxes with associated exon numbers. Sequence tag sites (STS) for which locations were not strictly constrained were spaced at roughly equidistant intervals between constrained markers. Polymorphic microsatellite markers are indicated with dotted lines. Note the large distance between exons 1 and 2 as well as between exons 4 and 5 . The crossover reported in Figure 3 occurred between 6-28-2 and exon 5 .

Two Hcrt polymorphisms were observed only in the multiplex family of poodles (Hcrt exon $1-75 \mathrm{C} \rightarrow \mathrm{A}$; Hcrt exon $2+67 \mathrm{G} \rightarrow \mathrm{A}$; A30T [Alanine $\rightarrow$ Threonine]) and were found not to segregate with disease susceptibility.

\section{A Novel Hcrtr2 Mutation Causing Autosomal Recessive Narcolepsy in a Dachshund Pedigree} A highly penetrant Hcrtr 2 mutation was observed in a Dachshund family. This mutation of Exon 1 $(461 \mathrm{G} \rightarrow \mathrm{A})$ results in a Glutamic acid $(\mathrm{E})$ to Lysine $(\mathrm{K})$ change at position 54 of the Hcrtr2 protein (E54K). The mutation is located at the level of the last amino acid 


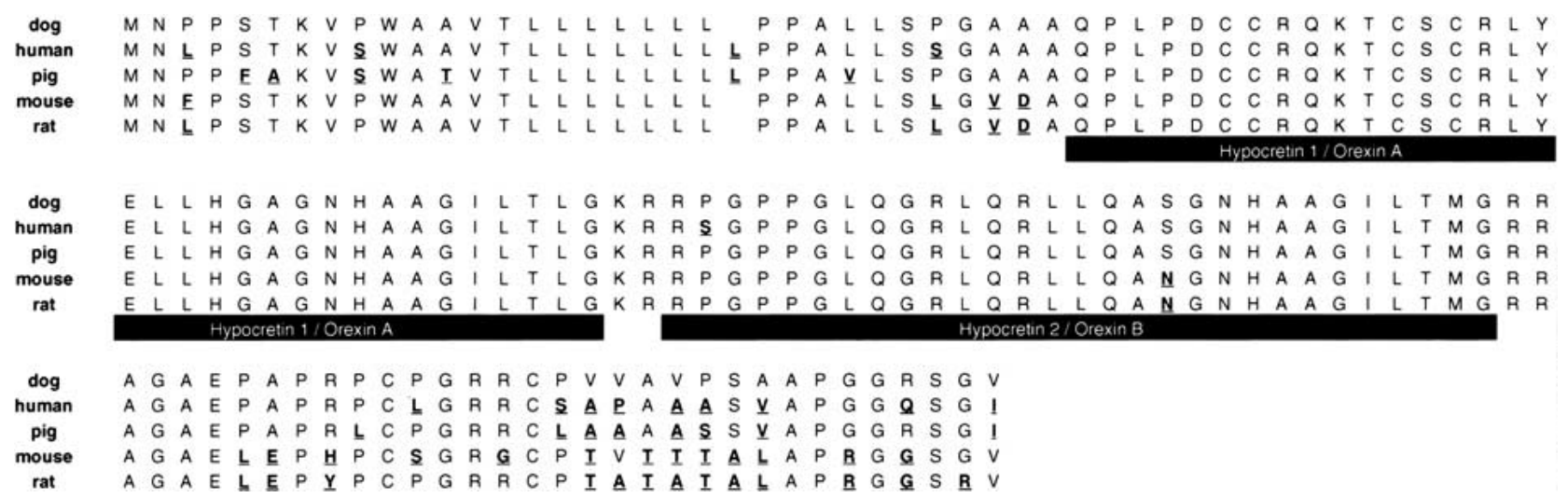

Figure 2 Deduced amino acid sequence of the canine preprohypocretin peptide and mature Hcrt-1 and Hcrt-2 peptides (black boxes). Sequences for other known species (human, rat, pig, and mouse) are indicated for comparative purposes. Variable residues are marked in black-underlined letters. Please note that while Hcrt-1 is identical in all species, canine and pig Hcrt-2 are identical but Hcrt-2 differs in other species.

of the N-terminal region of the receptor, immediately preceding the first transmembrane domain of the receptor. All three narcoleptic dogs born in the litter are homozygous for the substitution. The DNA change was not found in any other sporadic or familial narcoleptic canine or in healthy control dogs (144 chromosomes).

\section{Segregation Studies in Familial Narcolepsy}

All available Hcrtr 2 and Hcrt microsatellite markers and single-nucleotide polymorphisms were used to examine cosegregation with narcolepsy in multiplex family pedigrees. Results for Hcrtr2 and familial Doberman and Labrador narcolepsy have been reported previously (Lin et al. 1999). Of special interest was the observation of a crossover in the disease locus (Hcrtr2) in a member of the Dachshund family (Fritz; Fig. 3). The detailed mapping of the Hortr 2 gene revealed that this crossover occurred between 6-28-2 and exon 5 (Fig. 1A). Interestingly, narcolepsy in the Poodle pedigree did not cosegregate with Hcrtr2 or Hcrt markers (data not shown), indicating that another locus is most likely implicated. The exon 2 A30T amino acid substitution observed only in the Poodle family was a benign polymorphism located in the signal peptide region of Hcrt, with the unaffected father being homozygous for
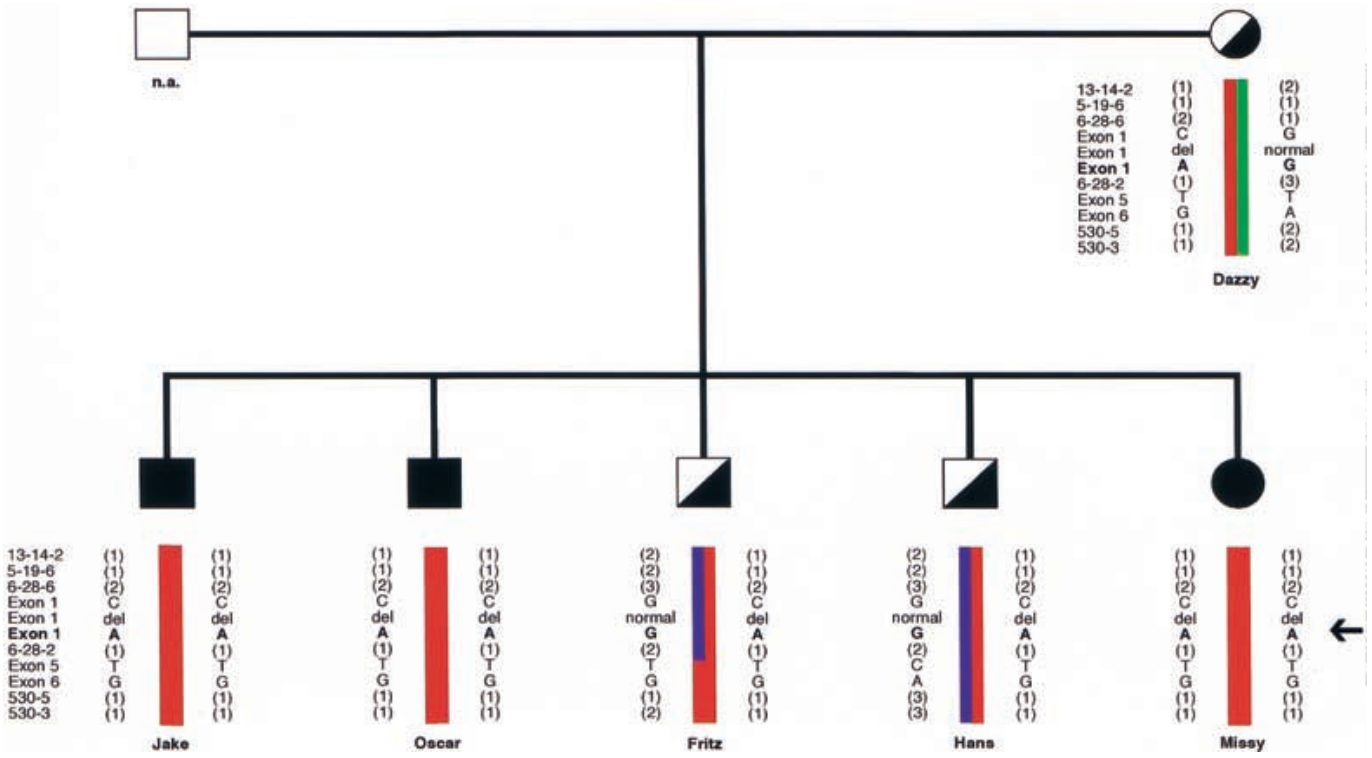

Figure 3 Mapping of an informative Hcrtr2 gene crossover observed in a litter of Dachshund with a recessive Hcrtr2 mutation causing narcolepsy. Six microsatellite markers located in the vicinity of Hcrtr2 were used (Lin et al. 1999, and Fig. 1A). Alleles are arbitrarily numbered by size and displayed in parenthesis. Five sequenced variants (four single nucleotides polymorphisms and a 3-bp deletion in exon 1) described in the Results section were also used. Note that the informative crossover occurred between marker 6-28-2 and exon 5 (Fig. 1A). The disease-causing mutation is the third polymorphism indicated in bold (exon 1, G/A). 
the substitution and all the offspring, whether affected or not, being heterozygous for this change. This hydrophobic to neutral substitution is located in a variable region of the signal peptide across species (Fig. 2).

Functional Analysis of the Mutated Hcrtr2 Receptors The functional effects of the two previously described exon-skipping Hcrtr2 mutations (Labradors and Dobermans) and of E54K were examined using Western blot analysis, expression of GFP tagged receptors, radioreceptor binding, and calcium flux studies in human embryonic kidney (HEK) 293 cells. Western blot analysis of mutated and wild-type expressed proteins indicated truncated Hcrtr2 in mutated Dobermans (55 kD) and Labradors $(65 \mathrm{kD})$ but not in wild-type or E54K mutated proteins (78 kD; data not shown). These results are in agreement with a predicted frame shift for these two corresponding exon-skipping mutations (Lin et al. 1999). In-frame GFP tags were added to the cDNA sequence of wild-type and mutant alleles to examine cellular localization in HEK-293 (see Methods). Fluores-

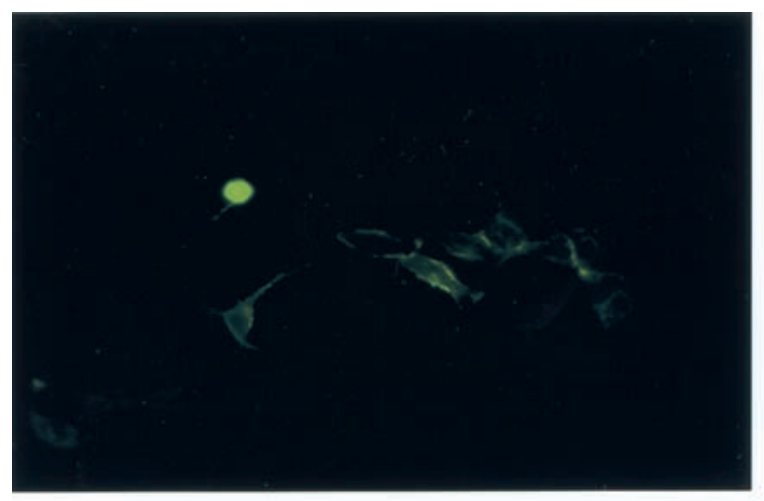

A

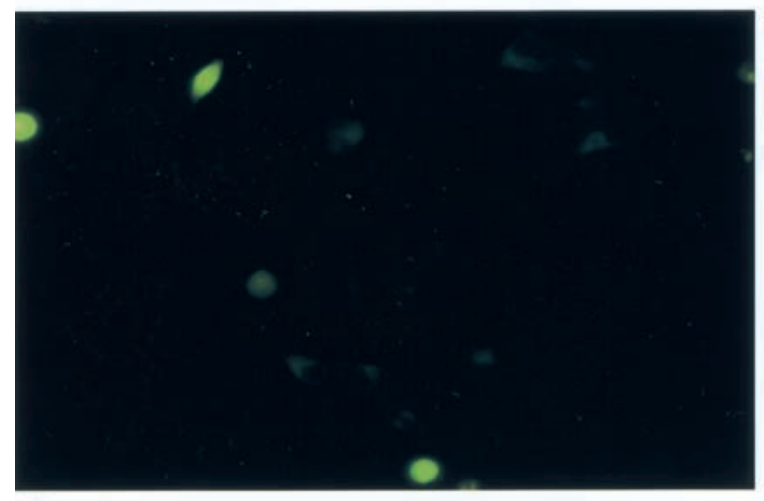

C

Figure 4 Localization of GFP-tagged mutated Hcrtr2 constructs in HEK-293 cells. Wild-type $(A)$ and E54K $(B)$ mutated constructs are expressed in the membrane, lining the surface of the cells. Truncated Hcrtr2 receptors of Doberman ( $C$ ) and Labrador $(D)$ mutants are cytoplasmically located.

\section{Genome Research} www.genome.org cence microscopy indicated that wild-type and E54Ksubstituted Hcrtr2 receptors were mostly expressed on the cell membrane, lining the shape of the cells (Fig. $4 \mathrm{~A}, \mathrm{~B})$. In contrast, exon-skipping mutated Hcrtr2 proteins were predominantly located intracytoplasmically, staining HEK cells (Fig. 4C,D) similar to control cells in which the GFP constructs were expressed (data not shown).

Radioreceptor binding studies were also performed in all Hcrtr2-transfected cells (with and without GFP tags), using $\left[{ }^{125} \mathrm{I}\right]$ Hcrt-1. Saturation studies in wildtype receptors indicated a $\mathrm{Kd}$ of $0.9 \mathrm{nM}$ for Hcrt-1. Further studies indicated no specific binding for all mutated receptors, even in E54K Hcrtr2-transfected cells known to express the receptor on its surface (Fig. 5). Lack of specific binding was demonstrated for this mutation even at saturating levels of radiolabeled ligand $(4 \mathrm{nM})$. We also evaluated functional effects of the transfected receptor by measuring $\mathrm{Ca}^{2+}$ influx in response to Hcrt- 1 and Hcrt-2 application $(0.25 \mathrm{nM}-1$ $\mu \mathrm{M})$. Calcium response to Hcrt-1 in wild-type receptors is shown in Figure 6. As expected, no response was

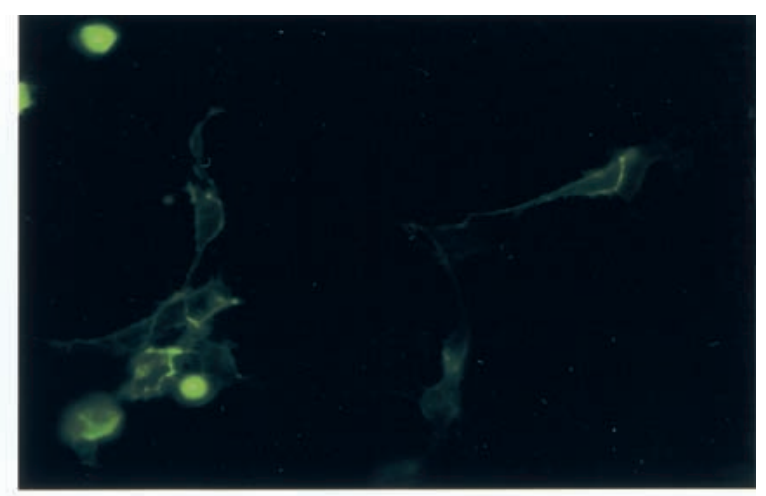

B

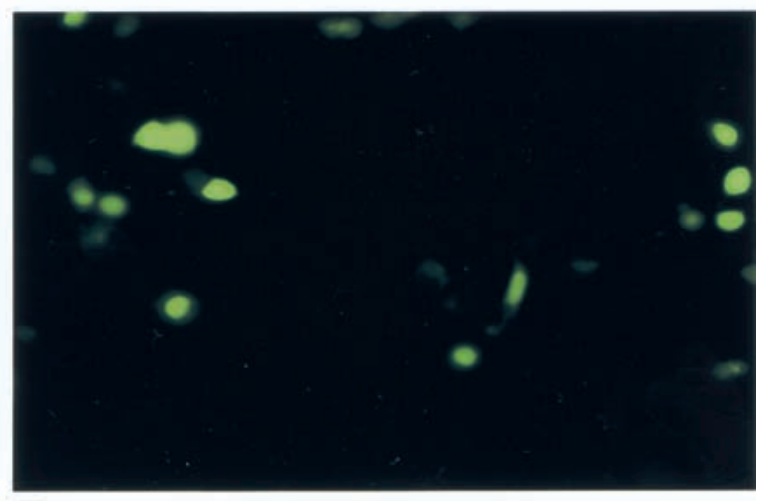

D 


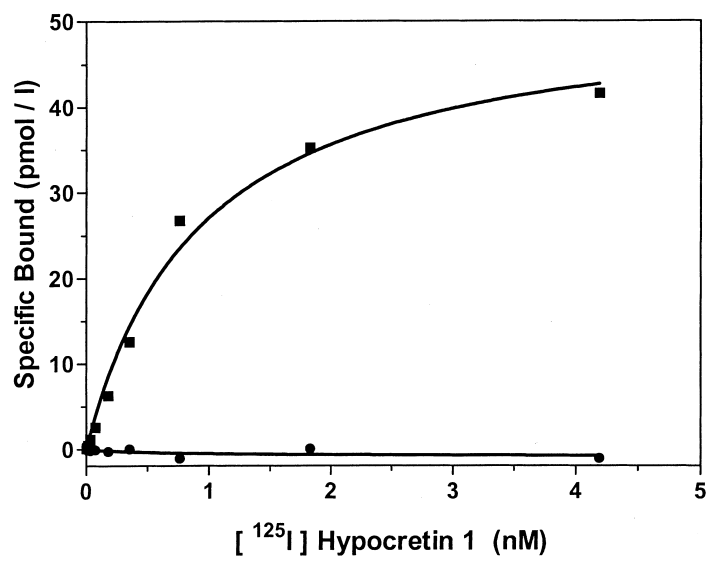

Figure 5 Radioreceptor-binding studies of wild-type (square symbol) and $\mathrm{E} 54 \mathrm{~K}$ (round symbol) mutated receptors using [ $\left.{ }^{125} \mathrm{I}\right]$ Hcrt-1. HEK-293 cells transfected with wild-type and mutated Hcrtr2 constructs with and without GFP were used (for technical details, see text). Note that wild -type receptors express saturable binding with an approximate $\mathrm{Kd}$ of $0.9 \mathrm{nM}$, while E54K does not bind the ligand at concentrations up to $4 \mathrm{nM}$. Data obtained with other mutated constructs are not shown, but the cells do not display any specific binding.

observed in cell lines transfected with the truncated Hcrtr2 mutated proteins of narcoleptic Dobermans and Labradors, even when up to $1 \mu \mathrm{M}$ of Hcrt-1 and Hcrt-2 were added (data not shown). The response of the substituted E54K Hcrtr2 receptor was more intriguing. A 1000 -fold reduced response was observed, with a $1-\mu \mathrm{M}$ concentration of Hcrt-1 weakly activating Calcium influx at levels similar to $0.25 \mathrm{nM}$ in wild-type receptors (Fig. 6). Results were identical whether or not the constructs were associated with a C-terminal GFP tag (data not shown).

\section{DISCUSSION}

In this study, we systematically screened the Hcrt and Hcrtr 2 loci in sporadic and familial cases of canine narcolepsy and identified only a single novel point mutation in the Hcrtr2 gene in a narcoleptic Dachshund multiplex family. The mutation, a $461 \mathrm{G} \rightarrow$ A substitution in exon 1, causes an amino acid change from Glutamic acid to Lysine (E54K) in the N-terminal part of the G-protein coupled receptor (GPCR). Functional analysis studies were performed for E54K and two previously-identified exon-skipping mutations. Results indicate a loss of function consistent with autosomal recessive transmission in these pedigrees and in vitro mutation data reported for other GPCR systems (Novotny et al. 1994; van Eyll et al. 1996; Pearce et al. 1996). Many naturally-occurring activating and deactivating mutations have been identified in various GPCR in a number of diseases (Spiegel 1998).

Functional studies in two exon-skipping mutations reported previosly in Labradors and Dobermans indicate a truncated receptor protein that is not even localized on the cytoplasmic membrane. The location of the skipping mutation predicts a 247 and a 330 amino acid protein in narcoleptic Dobermans and Labradors (as opposed to 444 for the wild type protein). Whereas the Doberman mutation is associated with a protein carrying only four of seven transmembrane domains and thus was rather unlikely to localize on the cell surface, the Labrador mutation is only truncated past the sixth transmembrane domain and could theoretically be normally translocated to the cell surface. Previous studies using other GPCR receptors have shown that truncated receptors may or may not be localized to the membrane or even bind their respective ligand (Schöneberg et al. 1995; Ho and MacKenzie 1999; Ling et al. 1999). The lack of membrane localization for the two Hcrtr2 mutants suggest that undetermined sequences in the last extracellular loop, the seventh transmembrane domain, and the C-terminal region of Hcrtr2 are necessary for proper cellular transport of the receptor.

Functional analysis of the E54K N-terminal substitution was more intriguing. The mutated receptor localizes to the membrane but does not bind Hypocretin at physiological concentrations (up to $4 \mathrm{nM}$ ). Interestingly, however, $\mathrm{Ca}^{2+}$ mobilization studies indicate that the receptor may still be activated by abnormally high ligand concentrations $(>1 \mu \mathrm{M})$ suggesting a very reduced but not absent affinity for Hcrt-1. This result parallels in vitro functional studies reported for similar mutations in other GPCR receptors. The N-terminal extracellular domain of GPCRs is critically important for agonist binding and resulting receptor activation (Couvineau et al. 1995; van Eyll et al. 1996; de Lucca et al. 1997). Single amino acid substitutions in the Nterminal region of the Glucagon-like peptide 1 receptor and/or human vasoactive intestinal peptide 1 receptors impair ligand binding and cAMP intracellular activation (van Eyll et al. 1996; Gaudin et al. 1998). Other $\mathrm{N}$-terminal substitutions can produce constitutive receptor activation, dominant diseases, and gain of function, for example, in sporadic hypoparathyroidism (de Lucca et al. 1997). Of importance is the fact that our substitution replaces a negatively charged Glutamic acid with a positively charged Lysine. The E54 residue is present for both Hcrtr1 and Hcrtr2 receptors in dogs, humans, pigs, and rats, suggesting a functionally important residue for Hypocretin binding (Sakurai et al. 1998; Lin et al. 1999). Changes in the charge distribution of the ligand-binding site of the N-terminal extracellular domain of GPCR often reduce or increase affinity of GPCRs for their ligand (Pearce et al. 1996; van Eyll et al. 1996).

The E54K mutation is the first example of a single amino acid substitution in the Hcrtr2 gene causing autosomal recessive canine narcolepsy. We conclude that the E54K and the two exon-skipping mutated Hcrtr2 

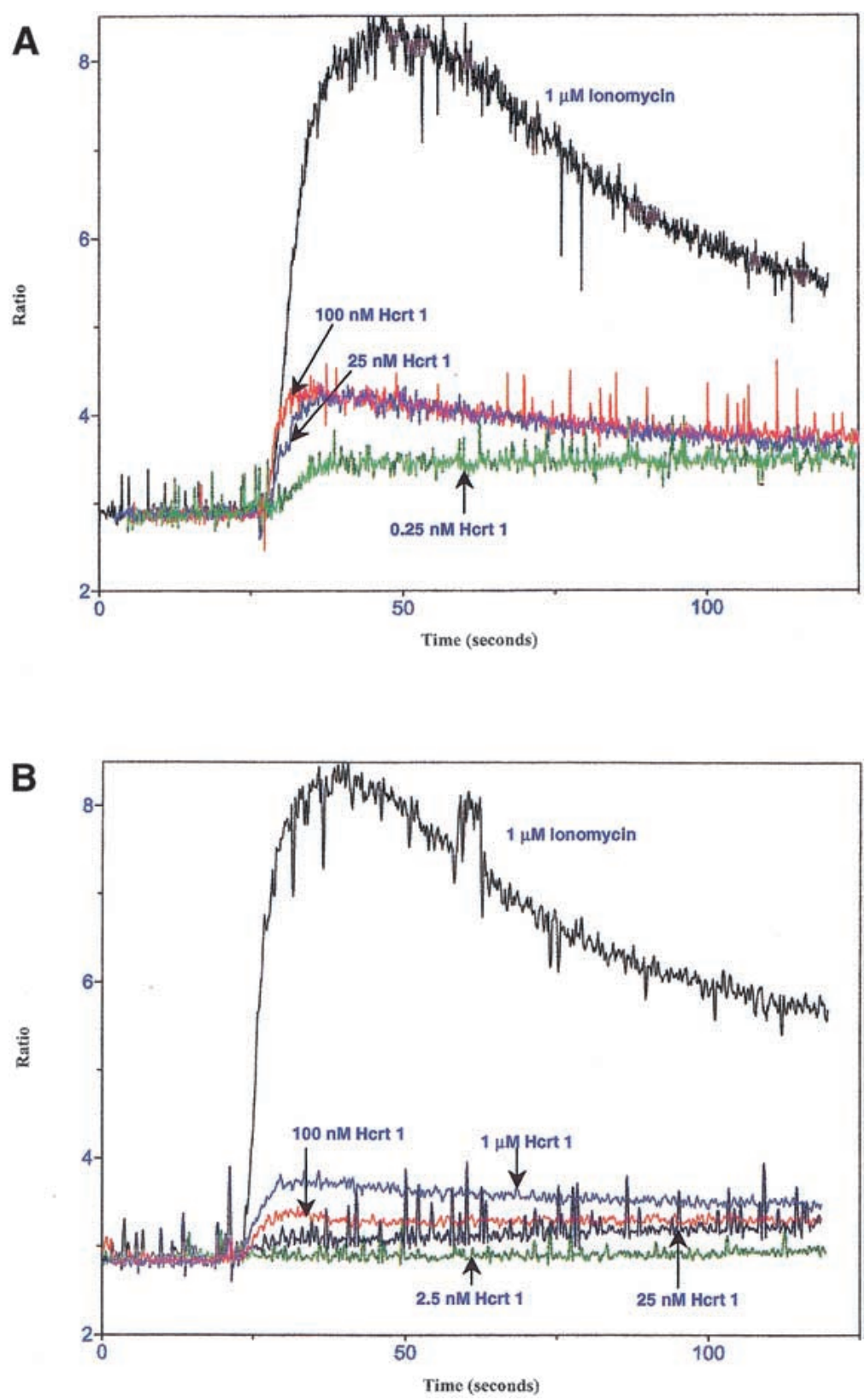

Figure $6 \mathrm{Ca}^{2+}$ influx after application of Hcrt-1 using wild type $(A)$ and $\mathrm{E} 54 \mathrm{~K}(B)$ receptors (for technical details, see Methods). lonomycin induces similar calcium influx in control and mutated receptors. Control receptors are activated at a higher level and by significantly lower Hcrt- 1 concentrations $(A)$ than the mutated E54K receptor. Similar results were obtained with Hcrt-2 (data not shown). Truncated mutants (Labrador and Doberman) did not react to Hcrt stimulation (see text).

lead to a complete loss of function consistent with autosomal recessive transmission. Interestingly, no other Hypocretin gene mutations were observed in 11 sporadic cases of narcolepsy or in one additional multiplex family of Poodles. This result parallels data observed in humans that indicate no hypocretin mutations in most cases (Peyron et al. 2000). In this recent study, a large number of familial and sporadic cases of human narcolepsy were screened for the Hcrt, Hcrtr1, and Hcrtr2 loci. Only one single mutation, a signal peptide alteration in the Hcrt locus producing dominant, severe, and early onset narcolepsy-cataplexy, was observed, indicating genetic heterogeneity. No Hcrtr2 mutations were reported in this study.

The lack of reported receptor mutations in familial human cases contrasts with the three reported Hcrtr2 mutations observed in canine narcolepsy. This finding could be explained by canine inbreeding in the face of recessive mutations, species-specific differences in mutation rates among loci, and/or differences in phenotype expression between animals and humans. In this vein, Hcrtr2-receptormutated mice have recently been shown to exhibit cataplexy and to have disturbed sleep patterns but may have a less severely affected phenotype than Hcrt knockout mice (Chemelli et al. 1999, 2000). This observation parallels data in canines indicating that Hcrtr2-mutated familial cases are generally less affected than are sporadic cases (Baker et al. 1982), now known to have undetectable Hcrtr-1 CSF levels (Ripley et al. 2001). In contrast, Hcrtr-1receptor knockout mice do not display cataplexy but have a milder degree of sleep fragmentation, suggesting a more minor but possibly significant role for Hcrtr-1 in the expression of the narcolepsy phenotype (Kisanuki et al. 2000). In this context, the lack of Hypocretin receptor mutations in human narcolepsy might also be explained by a milder phenotype for these alterations in humans versus other mammals.

The lack of mutations observed in most human and canine cases does not necessarily mean that Hypocretin system plays an insignificant role in most cases of narcolepsy. Deficient Hcrt neurotransmission is involved in most sporadic cases, with undetectable Hcrt-1 CSF levels and a dramatic loss of Hypocretin mRNA and peptides reported in human brains and in two sporadic cases of canine narcolepsy (Nishino et al. 2000; Peyron et al. 2000; Thannickal et al. 2000; Ripley et al. 2001). In human narcolepsy, the disorder is HLA-DQ associated (Mignot et al. 2001), and an autoimmune destruction of Hypocretin-containing cells has been postulated but not established for these cases. The absence of 
Hcrt mutations in sporadic cases of canine narcolepsy, together with undetectable CSF levels, may suggest similar pathophysiological mechanisms in sporadic canine narcolepsy cases. In contrast to human narcolepsy, however, canine narcolepsy is not associated with DLA-DQ (Wagner et al. 2000). This result could be explained by a different role of various MHC heterodimers in disease susceptibility across animal species. Additional neuropathological and genetic screening studies in human, mouse, and canine narcolepsy will in time answer these important questions.

\section{METHODS}

\section{Canine Patients and Controls}

A total of 78 dogs (17 with narcolepsy) were investigated in this study. All affected dogs had cataplexy (the pathognomonic feature of narcolepsy) when emotionally excited with food or playing. Most cases were initially diagnosed by veterinarians familiar with narcolepsy, and the diagnosis was confirmed with clinical interviews by one of the authors (E. M.). Three sporadic cases and most Doberman and Labrador familial cases were donated to the Center for Narcolepsy and had their diagnoses verified. Sporadic cases were typically more severely affected when compared to familial cases, had undetectable CSF Hypocretin-1 levels when tested ( $n=2$; Ripley et al. 2001), and had a later and more variable age of onset, as previously described (Baker et al. 1982). Familial cases included three affected Dachshunds in a multiplex family of six and three affected Poodles in a family of 13 Poodles. Ten affected Dobermans and 10 affected Labradors with previously-reported Hcrtr2 mutations were also investigated. These dogs have been shown to have normal CSF Hypocretin-1 levels (Nishino et al. 2000). Eleven sporadic cases (seven Poodles, three Dachshunds, and one Labrador) and 28 healthy dogs (10 Poodles, nine Dachshunds, seven Labradors, and two Dobermans) were also included.

\section{Canine BAC Library Screening}

The isolation of the Hcrtr2 loci was previously described in Lin et al. (1999). Attempts to screen the canine BAC library with human and rodent Hcrt probes were unsuccessful. Partial canine cDNA sequences were obtained using degenerate consensus PCR primers derived from rodent and human sequences. Total RNA was extracted from the cortex of two canines, one wild-type and one sporadic narcoleptic Dachshund, using RNeasy Maxi (QIAGEN). mRNA was purified from total RNA using Oligotex mRNA Midi Kits (QIAGEN). cDNA was synthesized using SuperScript II RT Kit (GIBCO BRL) and amplified using preproF:23 (5'CCCT GAGCKCCAGRCACCATGAA3') and preproR(Sal1):18 (5'CGCGTCGACGAGAMWCGTCTTTATTGCC3'). These primers were designed in the Hcrt gene according to known human, mouse, and rat cDNA sequences. PCR conditions were $95^{\circ} \mathrm{C}$ for $2 \mathrm{~min}$ and $35 \mathrm{cycles}$ of $94^{\circ} \mathrm{C}$ for $1 \mathrm{~min}, 56^{\circ} \mathrm{C}$ for $1 \mathrm{~min}$, and $72^{\circ} \mathrm{C}$ for $1 \mathrm{~min}$ and a final extension of $72^{\circ} \mathrm{C}$ for 5 min. cDNA sequences were analyzed on an ABI PRISM 377 DNA sequencer (Perkin Elmer). Probes designed using canine cDNA exon 1 and exon 2 sequences were found to be inappropriate for library screening. Exon 1 and exon 2 primers were thus designed to amplify and sequence intronic regions of the Hcrt locus using canine genomic DNA. F1
(5'AGAGCACTATAAACCCCAGACC3'; 5' end of exon 1 Hcrt) and dppR4 (5'AGTCTTYTGRCGACAGCAGTCG3'; first part of exon $2 \mathrm{Hcrt}$ ) were used to generate a 1079-bp PCR product, containing exon 1 , the intron region between exon 1 and 2 and the first part of exon 2 . PCR conditions were one cycle of $95^{\circ} \mathrm{C}(2 \mathrm{~min}) ; 10$ cycles of $94^{\circ} \mathrm{C}(1 \mathrm{~min}), 57^{\circ} \mathrm{C}(1 \mathrm{~min}), 72^{\circ} \mathrm{C}(1$ $\mathrm{min})$; followed by 30 cycles of $94^{\circ} \mathrm{C}(1 \mathrm{~min}), 55^{\circ} \mathrm{C}(1 \mathrm{~min})$, $72^{\circ} \mathrm{C}(1 \mathrm{~min})$; and ending with one cycle of $72^{\circ} \mathrm{C}(5 \mathrm{~min})$. This fragment was sequenced and used as a probe to screen our previously described Canine Genomic BAC Library (Li et al. 1999).

\section{Isolation and Testing of Polymorphic Markers}

Six previously described polymorphic markers (13-14-2, 5-196, 6-28-6, 6-28-2, 530-5, and 530-3) located in the vicinity of the canine Hcrtr2 gene were used in this study (Lin et al. 1999). Hcrt dinucleotide microsatellite markers were generated using Hcrt-positive BAC clones as described in Lin et al. (1999). Briefly, BAC clones were triple-digested with DraI, $S s p \mathrm{I}$, and EcoRV, and the fragments were ligated to pBluescript vector (Stratagene). The resulting transformation was plated on LB/Agar plates covered with a Duralose-UV membrane (Stratagene). The membrane was duplicated and hybridized with $\left[\gamma^{32} \mathrm{P}\right]$ dATP radiolabeled (CA)15, (GAAA)8, (GAAT)8, and/or (GATA) 8 oligonucleotides. Positives clones were cultured, extracted, and sequenced with $\mathrm{T} 3$ and $\mathrm{T} 7$ primers on an ABI 377 DNA sequencer. The program Primers (http://wwwgenome.wi.mit.edu/cgi-bin/primer/primer3_www.cgi) was used to design flanking primers on all sequence traces containing a repeat sequence $>10$ compound repeats. Amplification and detection of the fragment length polymorphism was performed as described in Lin et al. (1997).

\section{Hcrtr2 and Hcrt Contig Building and Sequencing}

Characterization of the canine Hcrtr2 locus was partially described in Lin et al. (1999). A similar approach was used to characterize the canine Hcrt locus. Direct BAC sequencing of the positive clones was performed to determine end sequences and to complete the characterization of exons, intron, and of at least 275-bp flanking boundaries. Sequence tag sequences (STS) primers were designed to amplify $\sim 200 \mathrm{bp}$ in the end of each BAC clone. Insert size was determined using NotI digestion followed by pulsed field gel electrophoresis in $1 \%$ agarose with CHEF-DR-II system (Bio-Rad), as described previously (Li et al. 1999). STS primer amplification, typing of polymorphic markers, sizing, and hybridization with selected Hcrt and Hcrtr 2 probes were used to organize the contigs for each respective loci.

\section{Mutation Screening of the Hcrtr2 and Hcrt Loci in Narcoleptic Canines}

Primers designed in the flanking $5^{\prime}$ and $3^{\prime}$ intron regions of Hcrtr2 (seven exons; Lin et al. 1999) and Hcrt (two exons) were used to amplify and sequence these loci. PCR primers and conditions are Hertr2, exon 1: EXON1F (5'ACCTCTTTGTTT GCCTCCCAG3') and EXON1R (5'GTGGGCTTCTGCTCTC ССТСТ $\left.3^{\prime}\right): 95^{\circ} \mathrm{C}(2 \mathrm{~min}) ; 30$ cycles of $94^{\circ} \mathrm{C}(1 \mathrm{~min}), 55^{\circ} \mathrm{C}(1$ $\min ), 72^{\circ} \mathrm{C}(1 \mathrm{~min})$; and $72^{\circ} \mathrm{C}(5 \mathrm{~min})$. Hcrtr2 Exon 2: 2INF (5'AGGGTCCCTTTTATAAAGGCAC3') and 2INR (5'GT GATCCTGGAGGCTCAAG ATC $\left.3^{\prime}\right): 95^{\circ} \mathrm{C}(2 \mathrm{~min}) ; 30$ cycles of $94^{\circ} \mathrm{C}(1 \mathrm{~min}), 56^{\circ} \mathrm{C}(1 \mathrm{~min}), 72^{\circ} \mathrm{C}(1 \mathrm{~min}) ;$ and $72^{\circ} \mathrm{C}(5 \mathrm{~min})$. Hcrtr2 Exon 3: 3INF (5'GAATCCAATTATCTGTGCAACC3') and 3INR (5'GCAGAGCTATTCAGTGAAATGG3'): 95 ${ }^{\circ} \mathrm{C}(2$ 
min), 30 cycles of $94^{\circ} \mathrm{C}(1 \mathrm{~min}), 56^{\circ} \mathrm{C}(1 \mathrm{~min}), 72^{\circ} \mathrm{C}(1 \mathrm{~min})$; and $72^{\circ} \mathrm{C}(5 \mathrm{~min})$. Hcrtr2 Exon 4: 4INF (5'ATATTGGGGGAG GAACAGAAGG3') and 4INR (5'GAAGGCTTGACTGTG GATAGCC $\left.3^{\prime}\right)$ : $95^{\circ} \mathrm{C}(2 \mathrm{~min}) ; 30$ cycles of $94^{\circ} \mathrm{C}(1 \mathrm{~min}), 56^{\circ} \mathrm{C}$ (1 min), $72^{\circ} \mathrm{C}(1 \mathrm{~min})$; and $72^{\circ} \mathrm{C}(5 \mathrm{~min})$. Hcrtr2 Exon 5: 5INF (5'AAGTATCCAGAACACTGTCCTTCC $3^{\prime}$ ) and EXSHCR-2R (5'GAAGGCTTGACTGTGGATAGCC $\left.3^{\prime}\right): 95^{\circ} \mathrm{C}(2 \mathrm{~min}) ; 10$ cycles of $94^{\circ} \mathrm{C}(1 \mathrm{~min}), 57^{\circ} \mathrm{C}(1 \mathrm{~min}), 72^{\circ} \mathrm{C}(1 \mathrm{~min}) ; 30$ cycles of $94^{\circ} \mathrm{C}(1 \mathrm{~min}), 55^{\circ} \mathrm{C}(1 \mathrm{~min}), 72^{\circ} \mathrm{C}(1 \mathrm{~min})$; and $72^{\circ} \mathrm{C}(5$ min). Hcrtr2 Exon 6: 6INF (5'GACTTCATTTGGCCTTTGATT TAC3') and 6INR (5'ACATTTGAAAACTCACCACTG AGA3'): $95^{\circ} \mathrm{C}(2 \mathrm{~min}) ; 10$ cycles of $94^{\circ} \mathrm{C}(1 \mathrm{~min}), 57^{\circ} \mathrm{C}(1 \mathrm{~min}), 72^{\circ} \mathrm{C}(1$ min); 30 cycles of $94^{\circ} \mathrm{C}(1 \mathrm{~min}), 55^{\circ} \mathrm{C}(1 \mathrm{~min}), 72^{\circ} \mathrm{C}(1 \mathrm{~min})$; and $72^{\circ} \mathrm{C}(5 \mathrm{~min})$. Hcrtr2 Exon 6/intron between Exon 6 and Exon 7/5' end of exon 7: 6EXF (5'GAGACCGTATATGCCTG GTTTACAT3') and 7EXR (5'TTTTGATACGTTGTCGAA ATT GCT3'): $95^{\circ} \mathrm{C}$ for $2 \mathrm{~min} ; 5$ cycles of $94^{\circ} \mathrm{C}(1 \mathrm{~min}), 58^{\circ} \mathrm{C}(1$ $\mathrm{min}), 72^{\circ} \mathrm{C}(1 \mathrm{~min}) ; 30$ cycles of $94^{\circ} \mathrm{C}(1 \mathrm{~min}), 55^{\circ} \mathrm{C}(1 \mathrm{~min})$, $72^{\circ} \mathrm{C}(1 \mathrm{~min})$; and $72^{\circ} \mathrm{C}(5 \mathrm{~min})$. Hcrtr2 Exon 7: 7INF (5'AAGAGTCTAGCAAGCTTCCCGTAA3') and 7INR (5'GCAAACAATCTGCAGGTAAGAGAT3'): $95^{\circ} \mathrm{C}(2 \mathrm{~min}) ; 30$ cycles of $94^{\circ} \mathrm{C}(1 \mathrm{~min}), 57^{\circ} \mathrm{C}(1 \mathrm{~min}), 72^{\circ} \mathrm{C}(1 \mathrm{~min})$; and $72^{\circ} \mathrm{C}$ (5 min). Hcrt Exon 1: Ex1pp01 (5'CTTGGCGGCCAT TCTTTG3') and EMR2 (5'GGCAGAGACACCTCAGCTT TCT $\left.3^{\prime}\right): 95^{\circ} \mathrm{C}(2 \mathrm{~min}) ; 30$ cycles of $94^{\circ} \mathrm{C}(1 \mathrm{~min}), 55^{\circ} \mathrm{C}(1 \mathrm{~min})$, $72^{\circ} \mathrm{C}(1 \mathrm{~min})$; and $72^{\circ} \mathrm{C}(5 \mathrm{~min})$. Hcrt Exon 2:ppdogintronF1 (5'CCAGAAAAGAGGAGTTCACTGC3') and 3'013 (5'GTCTC CGTACCACGGGGCCTC $\left.3^{\prime}\right): 95^{\circ} \mathrm{C}(2 \mathrm{~min}) ; 10$ cycles of $94^{\circ} \mathrm{C}$ $(1 \mathrm{~min}), 68.9^{\circ} \mathrm{C}(1 \mathrm{~min}), 72^{\circ} \mathrm{C}(1 \mathrm{~min}) ; 25$ cycles of $94^{\circ} \mathrm{C}(1$ $\mathrm{min}), 55^{\circ} \mathrm{C}(1 \mathrm{~min}), 72^{\circ} \mathrm{C}(1 \mathrm{~min}) ;$ and $72^{\circ} \mathrm{C}(5 \mathrm{~min})$.

PCR products were purified using the Qiaquick Kit (QIAGEN), amplified using the BigDye sequencing mix (PE Biosystems), column purified (Edge Biosystems), and sequenced in both directions on an ABI PRISM 377 DNA Sequencer (Perkin Elmer). Sequence alignments and trace comparisons were performed using Sequencher 3.11 (Gene Codes). cDNA-genomic DNA comparisons were performed using BLAST (http://www.ncbi.nlm.nih.gov/BLAST/). Polymorphism and mutation positions are reported with respect to the first base pair of each screened exon. Allele frequencies are reported for each sample of unrelated control animals of each breed when appropriate.

\section{Control and Mutated Hcrtr2 Constructs}

Total RNA was isolated from cerebral cortex of a narcoleptic Doberman, Doberman wild type, narcoleptic Labrador, and Labrador wild type, using the RNeasy Mini Kit (QIAGEN). First-strand cDNA was made with a cDNA synthesis kit (Life Technologies). To clone the Hypocretin receptors from wildtype dogs and dogs with narcolepsy, PCR primers were generated corresponding to the $5^{\prime}$ end of the coding sequence (5'-aaggttaggatccgagccgga ctcgagcccgtgatgtcc- $\left.3^{\prime}\right)$ and the 3 ' end of the coding sequence $\left(5^{\prime}\right.$-aaccttaag ctttcctgtcatatgaat gaatgttcta- $3^{\prime}$ ) of the Hypocretin 2 receptor. PCR amplification was performed using the following conditions: $95^{\circ} \mathrm{C}(2 \mathrm{~min})$; 35 cycles of $95^{\circ} \mathrm{C}(40 \mathrm{sec}), 63^{\circ} \mathrm{C}(40 \mathrm{sec}), 72^{\circ} \mathrm{C}(2 \mathrm{~min})$; and $72^{\circ} \mathrm{C}$ (5 min). The PCR-amplified material was fractionated by agarose gel electrophoresis, and a fragment of $\sim 1.3 \mathrm{~kb}$ was isolated, amplified, and cloned into the expression vector pCDNA3.1(-) (Invitrogen). The Hypocretin 2 receptor from a Dachshund that has narcolepsy was generated by mutating the wild-type receptor based on the genomic sequence of the Hypocretin 2 receptor found in Dachshunds with narcolepsy.
All of the above constructions were confirmed by sequencing using an Applied Biosystems 377 automated sequencer (Perkin Elmer). The three mutated and the wild-type Hcrtr 2 constructs without a stop codon were also subcloned into pEGFPN3 (Clontech), which contains the gene for GFP, and the subsequent translated protein, which contains a GFP tag at the $\mathrm{C}$ terminus.

\section{Expression of Control and Mutated Alleles in HEK-293}

Stable cell lines expressing dog Hcrtr2 were created by transfecting the constructions into HEK-293 cells using Effectene (QIAGEN). Cells were cultured in Dulbecco's modified Eagle's medium (GIBCO BRL) supplemented with 10\% fetal bovine serum, $2 \mathrm{mM}$ glutamine, $1 \mathrm{mM}$ pyruvate, $10 \mathrm{mM}$ Hepes, $50 \mathrm{U}$ penicillin, and $50 \mu \mathrm{g} / \mathrm{mL}$ streptomycin. G418 (200 $\mu \mathrm{g} / \mathrm{mL})$ was added after $2 \mathrm{~d}$ to the media as a selection agent and cultures grown for $4 \mathrm{wk}$. GFP-tagged receptor-expressing cell lines were observed under inverted fluorescence microscopy (Nikon Eclipse TE300). Fluorescence images were captured with a Spot Digital Camera (Diagnostic Instruments) with standard FITC filter sets, using a $20 \times$ objective lens and analyzed by Image Pro Analysis Software (Media Cybernetics).

\section{Radioreceptor-Binding Studies and Measurements of intracellular $\mathrm{Ca}^{2+}$ in Transfected Cell Lines}

Receptor binding assays were performed using [ [ $\left.{ }^{125} \mathrm{I}\right]$ Hypocretin-1 (NEN) in Dulbecco's modified medium with $0.1 \%$ BSA. Cold Hypocretin-1 and Hypocretin-2 peptide, (human sequence) were synthesized at Neurocrine Biosciences. HEK-293 cells were released using $10 \mathrm{mM}$ EDTA $(10 \mathrm{mM})$ and washed twice with Dulbecco's modified medium. In each tube, approximately one million cells were added to $1 \mathrm{~mL}$ of Binding buffer (Dulbecco's modified medium containing 0.1\% BSA) and $30 \mathrm{pM}$ of $\left[{ }^{125} \mathrm{I}\right]$ Hcrt-1. To determine nonspecific binding in each case, $1 \mu \mathrm{M}$ of cold Hcrt-1 was added. For the saturation binding experiment, 5-0.01 nM $\left[{ }^{125} \mathrm{I}\right]$ Hcrt-1 (with twofold series dilution) were added to each tube with $1 \mu \mathrm{M}$ cold Hcrt-1 (nonspecific) or without cold Hcrt-1 (total binding) in triplicate. The binding mixture was incubated for $40 \mathrm{~min}$ at room temperature. Cells were centrifuged at $3000 \mathrm{rpm}$ for 5 min, and cell pellets were counted for bound $\left[{ }^{125} \mathrm{I}\right] \mathrm{Hcrt}-1$ in a $\gamma$ counter (Packard). Binding studies were analyzed using PRIZM (GraphPad Software).

Calcium release on activation of the Hypocretin receptors expressed in HEK-293 was examined. HEK-293 cells expressing either the wild-type or mutant Hcrtr2 receptors were plated onto 60-mm dishes. After the cells grew to confluency, the cells were washed with Dulbecco's modified medium containing 10\% fetal bovine serum and $3 \mu \mathrm{M}$ Indo- 1 (Molecular probe) and pluronic acid $(0.01 \%)$ and incubated at $37^{\circ} \mathrm{C}$ for 40 min. The cells were then released from the dish by the addition of $10 \mathrm{mM}$ EDTA, washed twice with PBS, and then suspended in Hanks buffer containing $1 \mathrm{mM} \mathrm{MgCl}_{2}, 5 \mathrm{mM}$ Glucose, $20 \mathrm{mM}$ Hepes. The PTI Fluorescence System hardware and Felix software (PTI) were used to analyze intracellular $\mathrm{Ca}^{2+}$ mobilization in response to various concentrations of human Hcrt-1 and Hcrt-2.

\section{Western Blot Analysis of Translated Products}

SDS loading buffer containing $100 \mathrm{mM}$ DTT was added to whole-cell lysis or membranes, and the samples were run on 
an 8\%-16\% SDS-polyacrylamide gel. Proteins were transferred onto a PDV membrane, blocked with 5\% nonfat milk in TBST, incubated with anti-GFP anti body (Zymed) and then horseradish peroxidase conjugated goat anti-mouse IgG (Fc specific; Sigma), and detected with ECL system (Amersham Life Sciences).

\section{ACKNOWLEDGMENTS}

This work was supported by National Institutes of Health (NS23724, NS33797, and HL59601) (E.M.), Deutsche Forschungsgemeinschaft (HU 827/2-1) (M.H.), and Neurocrine Biosciences (J.F., R.A.M). We thank Anna Voros for her excellent technical support; Seiji Nishino, Robin Li, Hiroshi Kadotani, Juliette Faraco, Will Rogers, Mario Pedrazzoli, and Michele Okun for their experimental, technical, and scientific contributions to this work; and Claudia Gumbiner for editing the manuscript.

The publication costs of this article were defrayed in part by payment of page charges. This article must therefore be hereby marked "advertisement" in accordance with 18 USC section 1734 solely to indicate this fact.

\section{REFERENCES}

Aldrich, M.S. 1998. Diagnostic aspects of narcolepsy. Neurology 50: S2-S7.

Anic-Labat, S., Guilleminault, C., Kraemer, H.C., Meehan, J., Arrigoni, J., and Mignot, E. 1999. Validation of a cataplexy questionnaire in 983 sleep-disorders patients. Sleep 22: 77-87.

Baker, T.L., Foutz, A.S., McNerney, V., Mitler, M.M., and Dement, W.C. 1982. Canine model of narcolepsy: Genetic and developmental determinants. Exp. Neurol. 75: 729-742.

Chemelli, R.M., Willie, J.T., Sinton, C.M., Elmquist, J.K., Scammell, T., Lee, C., Richardson, J.A., Williams, S.C., Xiong, Y., Kisanuki, Y., et al. 1999. Narcolepsy in orexin knockout mice: Molecular genetics of sleep regulation. Cell 98: 437-511.

Chemelli, R.M., Sinton, C.M., and Yanagisawa, M. 2000. Polysomnographic characterization of Orexin-2 receptor knockout mice. Sleep 23: (Suppl.) 296-297.

Couvineau, A., Gaudin, P., Maoret, J.J., Rouyer-Fessard, C., Nicole, P., and Laburthe, M. 1995. Highly conserved Aspartate 68, Tryptophane 73 and Glycine 109 in the N-terminal extracellular domain of the human VIP receptor are essential for its ability to bind VIP. Biochem. Biophys. Res. Commun. 206: 246-252.

de Lucca, F., Ray, K., Mancilla, E.E., Fan, G.F., Winer, K.K., Gore, P., Spiegel, A.M., and Baron J. 1997. Sporadic hypoparathyroidism caused by de novo gain of function mutations of the $\mathrm{Ca}^{2+}$-sensing receptor. J. Clin. Endocrino. Metab. 82: 2710-2715.

Gaudin, P., Maoret, J.J., Couvineau, A., Rouyer-Fessard, C., and Laburthe, M. 1998. Constitutive activation of the human vasoactive intestinal peptide 1 receptor, a member of the new class II family of G protein-coupled receptors. J. Biol. Chem. 273: 4990-4996.

Ho, G. and MacKenzie. R.G. 1999 Functional characterization of mutations in melanocortin-4 receptor associated with human obesity. J. Biol. Chem. 274: 35816-35822.

Kisanuki, Y.Y., Chemelli, R.M., Sinton, C.M., Williams, S.C., Richardson, J.A., Hammer, R.E., and Yanagisawa, M. 2000. The role of orexin receptor Type-1 (OX1R) in the regulation of sleep. Sleep 23: (Suppl.) 91.

Li, R., Mignot, E., Faraco, J., Kadotani, H., Cantanese, J., Zhao, B., Lin, X., Hinton, L., Ostrander, E., Patterson, D., and de Jong, P. 1999. Construction and characterization of an eightfold redundant dog genomic bacterial artificial chromosome library. Genomics 58: 9-17.

Lin, L., Jin, L., Kimura, A., Carrington, M., and Mignot, E. 1997. DQ microsatellite association studies in three ethnic groups.
Tissue Antigens 50: 507-520.

Lin, L., Faraco, J., Li, R., Kadotani, H., Rogers, W., Lin, X., Qiu, X., de Jong, P.J., Nishino, S., and Mignot, E. 1999. The sleep disorder canine narcolepsy is caused by a mutation in the Hcrt (orexin) receptor 2 gene. Cell 98: $365-376$.

Ling, K., Wang, P., Zhao, J., Wu, Y.L., Cheng, Z.J., Wu, G.X., Hu, W., Ma, L., and Pei, G. 1999. Five-transmembrane domains appear sufficient for a $\mathrm{G}$ protein-coupled receptor: Functional five-transmembrane domain chemokine receptors. Proc. Natl. Acad. Sci. 96: 7922-7927.

Mignot, E. Genetic and familial aspects of narcolepsy. 1998. Neurology 50: S16-S22.

Mignot, E., Guilleminault, C., Dement, W.C., and Grumet, F.C. 1992. Genetically determined animal models of narcolepsy, a disorder of REM sleep. In Genetically definied animal models of neurobehavioral dysfunction (ed. P. Driscoll), pp.89-110. Birhäuser, Boston.

Mignot, E., Tafti, M., Dement, W.C., and Grumet, F.C. 1995 Narcolepsy and Immunity. Adv. Neuroimmunol. 5: 23-37.

Mignot, E., Lin, L., Rogers, W., Honda, Y., Qiu, X., Lin, X., Okun, M., Hohjoh, H., Miki, T., Hsu, S.H., et al. 2001. Complex HLA-DR and DQ interactions confer risk for narcolepsy-cataplexy in three ethnic groups. Am. J. Hum. Genet. (in press).

Nishino, S. and Mignot, E. 1997. Pharmacological aspects of human and canine narcolepsy. Prog. Neurobiol. 52: 27-78.

Nishino, S., Ripley, B., Overeem, S., Lammers, G.J., and Mignot, E. 2000. Hypocretin (orexin) deficiency in human narcolepsy. Lancet 355: 39-40.

Novotny, E.A., Bednar, D.L., Connolly, M.A., Connor, J.R., and Stormann, T.M. 1994. Mutation of aspartate residues in the third extracellular loop of the rat b2 Bradikinin receptor decrease affinity for bradykinin. Biochem. Biophys. Res. Comm. 201: 523-530.

Pearce, S.H.S., Bai, M., Quinn, S.J, Kifor, O., Brown, E.M., and Thakker, R.V. 1996. Functional characterization of calcium-sensing receptor mutations expressed in human embryonic kidney cells. J. Clin. Investig. 98: 1860-1866.

Peyron, C., Faraco, J., Rogers, W., Ripley, B., Overeem, S., Charnay, Y., Nevsimalova, S., Aldrich, M., Reynolds, D., Albin, R., et al. 2000. A mutation in early onset narcolepsy and a generalized absence of Hypocretin peptides in human narcoleptic brains. Nat. Med. 6: 991-997.

Ripley, B., Fujiki, N., Okura, M., Mignot, E., and Nishino, S. 2001. Hypocretin levels in sporadic and familial cases of canine narcolepsy. Neurobiol. Dis. (in press).

Sakurai, T., Amemiya, A., Ishii, M., Matsuzaki, I., Chemelli, R.M., Tanaka, H., Williams, S.C., Richardson, J.A., Kozlowski, G.P., Wilson, S., et al. 1998. Orexins and orexin receptors: A family of hypothalamic neuropeptides and $\mathrm{G}$ protein-coupled receptors that regulate feeding behavior. Cell 92: 573-585.

Schöneberg, T., Liu, J., and Wess, J. 1995. Plasma membrane localization and functional rescue of truncated forms of a $\mathrm{G}$ protein-coupled receptor. J. Biol. Chem. 270: 18000-18006.

Spiegel, A.M. 1998. G proteins, receptors and disease. Humana, Totawa, NJ.

Thannickal, T.C., Moore, R.Y., Nienhuis, R., Ramanathan, L., Gulyani, S., Aldrich, M., Cornford, M., and Siegel, J.M. 2000. Reduced number of Hypocretin neurons in human narcolepsy. Neuron 27: 469-474.

Van Eyll, B., Göke, B., Wilmen, A., and Göke, R. 1996. Exchange of W39 by A within the N-terminal extracellualr domain of the GLP-1 receptor results in a loss of receptor function. Peptides 17: $565-570$.

Wagner, J.L., Storb, R., Storer, B., and Mignot, E. 2000. DLA-DQB1 alleles and bone marrow transplantation experiments in narcoleptic dogs. Tissue Antigens 56: 223-231.

Received August 16, 2000; accepted in revised form January 25, 2001 
Genome Research 11: 531-539 (2001)

Identification and Functional Analysis of Mutations in the Hypocretin (Orexin) Genes of Narcoleptic Canines

Marcel Hungs, Jun Fan, Ling Lin, Xiaoyan Lin, Richard A. Maki, and Emmanuel Mignot

The name of Dimitri Grigoriadis was not included in the author list appearing in the Table of Contents and article title page. The full author list is as follows:

Marcel Hungs, Jun Fan, Ling Lin, Xiaoyan Lin, Dimitri Grigoriadis, Richard A. Maki, and Emmanuel Mignot 


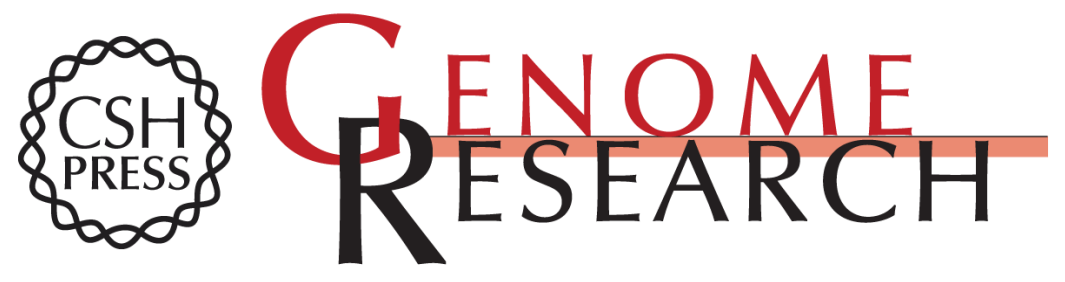

\section{Identification and Functional Analysis of Mutations in the Hypocretin (Orexin) Genes of Narcoleptic Canines}

Marcel Hungs, Jun Fan, Ling Lin, et al.

Genome Res. 2001 11: 531-539

Access the most recent version at doi:10.1101/gr.161001

Related Content Errata for vol. 11, p. 531

Genome Res. May, 2001 11: 919

License

Email Alerting Receive free email alerts when new articles cite this article - sign up in the box at the Service top right corner of the article or click here.

\section{Affordable, Accurate} Sequencing.

To subscribe to Genome Research go to:

https://genome.cshlp.org/subscriptions 